days later he had a sudden attack of angina pectoris from which he made a slow recovery.

Urine high color; specific gravity 1,018; very small trace of albumen; in the sediment a fow hyaline casts were found.

Since November, 1888, there have been no severe attacks of angina. The action of the heart is very irregular, at times intermittent. In the spring of 1889, the albumen and casts disappeared from the urine. During the last year there has been slight albuminuria, dependent upon cystitis secondary to an eulargement of the prostate.

He has never been able to lead an active life, although for some time he could walk out, and now can drive.

I have observed several cases of albuminuria with the appearance of casts in the sediment associated with acute febrile attacks, namely, pneumonia, severe tonsillitis, typhoid, etc. In these cases there was always complete recovery within a few days or weeks subsequent to the subsidence of the fever. The anatomical busis for such cases of trausient albuminuria is undoubtedly to be found in the pathological lesion described as granular degeneration or by the more general name "cloudy swelling." Three cases were associated with pregnancy in the last few monthe.

Case I. Young primipara. No symptoms suggestive of renal disease. Three weeks before delivery the urine was yellow; specific gravity 1,021 ; small trace of albumen; in the sediment a fow hyaline and fine granular casts. The albumen soon became more abundant, othorwise no bad symptoms.

'Three days before delivery the urine was smoky in color, ove-half per cent. of albumen; specific gravity 1,022. Amount not diminished. In sediment very numerous hyaline and fine granular casts; some blood. A little fat on a few of the casts.

Five days after delivery the urine contained only a small trace of albumen, and in the sediment no casts wero found.

In a subsequent pregnancy, two years later, the urine was not abnormal in any respect.

CAsc II. Second pregnancy. Slight œdema, otherwise no renal symptoms. Urine was yellow in color; albumen, one-fourth per cent. ; in sediment a few fine granular casts. In this case the albuminuria and casts continued for several weeks after delivery. No impairment of general health in any way. In her first and third pregnancies the urine was normal in all respects.

Case III. Again no renal symptoms, though the urine contained one-fourth per cent. of albumen aud numerous casts. In all these cases the urine was normal in amount, and the urea, when tested, was normal or increased in amount.

Finally, I will briefly mention a few miscellaneous cases.

Casc I. A gentleman past middle life first noticed that he had to pass water very frequently. General health not robust. He took but little exercise. Heart not abnormal.

Urine rather pale; specific gravity, 1,016; small trace of albumen; in the sediment numerous crystals of calcic oxalate acid and a few hyaline casts. Urine increased in amount; urea normal. The oxaluria and casts lasted four weeks and then disappeared. No cause for the albuminuria could be discovered except the oxaluria. The frequency of micturition disappeared with the ocher symptoms noted.

CASE II. A man apparently in perfect health, had two years ago a sharp attack of renal colic. During the attack the urise contained a small amount of albumen and numerous casts; nlso numerous epithelial cells similar to those found in the pelvis of the kidney. No return of renal colic or albuminuria.

CASE III. Young man, twenty years old. Until the spring of 1889 hud always considered himself well. During the summer he found that he was easily tired. In September, 1889, examination of the urine showed one-fourth per cent. of albumen; in the sediment a good many hyaline and granular casts; a fow blood globules. He had no headuche or vomiting, no cedema ; color good. No enlargement or other change of the heart.

In November, 1889, the examination of the urine was practically the same except that some of the casts contained fat, and a few fatty degenerated epithelial cells were found.

During January and February, 1890, he was in the South; and a specimen of urine received February 13 th, showed an absence of casts; a very small trace of albumen. On his return in the spring of 1890 the urine again contained albumen and casts. In July, 1890 , arsenic was found in the urine; and examination of the wall paper of his bedroom showed that it coutained a good deal of arseuic. This winter he has passed in Asheville, and the last examination of the urive, made in December, 1890 , showed a very small amount of albumen and an occasional cast.

In the absence of auy symptoms pointing to nephritis, except the examination of the urine, and the marked improvement when he was away from home, I think it is reasonable to suppose that the albuminuria and casts may have been due to fatty degeneration, the result of arsenic.

As in cases of heart disease, we base our prognosis on the condition of the muscular tissue of the heart walls and the rate and rhythm of the pulse, and not upon the murmur heard, so in cases of kiduey disease we can only judge of the real condition of our patient by knowing the amount of urea and water excreted, which informs us of the actual power of the kidney to perform its work.

I think I have shown that renal albuminuria may be due to many distinct lesions, and I wish especially to draw the attention of the Society to the two cases of chronic albuminuria with casts, in which arsenic was found in the urine.

\section{AN EPIDEMIC OF INFLUENZA.}

\author{
BY s. G. WEBHEH, a.D., \\ Superintendent Adams Nervine Asylum.
}

During the latter part of March an epidemic of the grippe began at the Adams Nervine Asylum. Several features of the disease were different from any which I saw a year ago, and as being peculiur, seem to me to deserve notice.

Between March 18th aud 30th, twenty-eight cases occurred. 'This was a period of dull, rainy and damp weather. 'There was then a change and we had a few days of sunshine, during which no new cases appeared. Then a day or two before a storm there were more 
cases, and in four days they numbered eleven. One case preceded March 18th, and its nature was not recognized until other cases occurred later.

Several of the patients were so slightly affected that they were not obliged to give up, and it is possible that one or two cases may have escaped notice. Forty persons are known to have been affected. 'Twentyseven were confined to their beds from half a duy to ten days. Four of five amoug the nurses continued at work, though with much discomfort, and only by great exertion of will. Only sixteen can be said to have had the discase severely.

The first symptoms were generally, pain in head and back, with lassitude, often aching of the limbs. Sometimes the patient said she felt as if she had caught a severe cold.

About the same time with the above pains and aches, sometimes as the first noticeable symptom, the throat became sore. 'This was present in almost every case. 'There were only one or two cases without the sore throat. In thirteen patients this synptom was not severe, and closely resembled an ordinary sore throat. In only a few of these thirteen were the tonsils enlarged.

In the other twenty-seven cases the tousils were enlarged, the follicles inflamed and filled with secretions. In some cases the white patches were very large covering half or more of a tonsil.

In many cases the soft palate was dotted over with bright red points or pimples, and later when the soft palate was uniformly red, this was of a very dark shade. In a few cases instead of the follicles being especially affected, the fauces as a whole, including the tousils, the pillars, the soft palate and the posterior wall, was of a durk port-wine color.

In eleven cases the tonsils were very much swolleu so as to interfere with deglutition, not only by the pain, but by their sixe. In such cases the voice had a nasul toue, and in a few cases this tone was noticeable where the tousils were not very large, or it appeared a few days later when the swelling was sub. siding, as if due to a weakness of the muscles.

In only one case was there an abscess found in the tonsil, and that appeared after the disease had nearly run its course, the initial tonsillitis had subsided, and was probably due to imprudence in exposure to draughts of air.

Another early and constant symptom was the fever, the temperature rose rapidly, within a few hours to $102^{\circ}$ or higher. In one case at $6 \mathrm{P}$. M., the temperature was $99.8^{\circ}$; at 9, r. M. it was $101.8^{\circ}$. 'The highest temperature noticed was $103.8^{\circ}$. Within twentyfour or thirty-six hours of the onset, the temperature reached the highest point, then gradually it dropped. If the general affection was not severe the temperature fell quickly. If the other symptoms continued, the temperature remained between $100^{\circ}$ and $102^{\circ}$ for a few days, then dropped to normal. 'The pulse was rather rapid, 120 or more; sometimes lacked in strength. When the temperature subsided, the pulse usually fell to about 100 .

Less constant than the symptoms already mentioned was coryza. 'This was noticed in many cuses a few days after the beginning of the disease. It could scurcely be called an initial symptom.

Niue of the patients had an eruption, varying from a slight erythematous redness, affecting ouly the face, to a general eruption, affecting the body and limbs.
This did not appear before the fourth day, and was in some cases delayed a week. It resembled measles very closely, and was followed by enfoliation of the cuticle; in the severest cases the skin peeling off in large flakes.

An eruption of herpes on the lips was noticed in five or six cases. In two cases this was quite extensive. Among later and rurer'symptoms may be mentioned nausea and vomiting, in only a few, but in some very persistent and troublesome; cough, persisting through several days, in a larger number; oppression across the chest, in three or four.

More general later symptoms were weakness, continuing several days or weeks, but less extreme than a year ago; aching of the back and limbs continuing for many days after the other symptoms, except weakness, had ceased.

The lighter cases required but little treatment. The severer cases were relieved of pain and aching by phenacetin in ten or twenty grains. 'Throats were sprayed with a solution of iodoform in ether, which caused considerable smarting and irritation at first, but soothed the discomfort later. A gargle of chlorute of potassa or alum also gave relief to the throat, and was especially grateful after the tonsillitis had subsided. For general treatment it was simply necessary to sustain the patient's strength. Anointing with oil was used to relieve the annoyance caused by the eruption, but was not of much benefit.

\section{Elinical EDepartment.}

\section{CASE OF ACUTE LOCAL GDDEMA COMIII-} CA'TED WI'TH PURPURA AND SALIVA'IION.

RGPORTE HY WALTKR JT, JOLMLS, M.D., WATKHIURY, CONN.

A casw of that singular disease, acute local edema, similar to those reported by Dr. Robert W. Lovett of Boston, in the Journal of October 30, 1890, occurred lately in my practice, aud, in view of the rarity and ill-understood nature of the disease, seems worth reporting.

Edward Gunning, a laborer, who up to that time had been in excellent health, was taken on April 1, 1891 , with a sudden painless swelling of his left great toe, which was of a dark red color. 'Ihirty-six hours later his whole left foot swelled to a little above the ankle and was swollen for five days.

I saw him on April 8th, by which time the swelling in his foot and ankle had completely subsided. 'There was then a swelling over the middle of the right ulna, sharply circumscribed, about the size of half a hen's egg. The left forearm was swollen to the elbow. These swellings had the color of tho normal skin, were painless and would pit somewhat on pressure, the depression however, quickly filling up again. The next day both hands were swollen, the right arm to a little above the elbow, and there were many purpuric spots on the flexor sides of both elbows. Both lower extremities on the second day were covered with purpuric spots, varying from the size of the end of a tinger to that of a silver dollar. 'There was at no time any blood in the urine nor any hemoptysis. Both arms were bandaged snugly with flannel bandages cut on the bias. The arms were swollen for not more than two days, but the left hand for three. 